\title{
The occurrence of metacercariae of Petasiger (Digenea: Echinostomatidae) in an unusual site, within the lateral line scales of cyprinid fishes
}

\author{
Kálmán Molnár ${ }^{1}$, David I. Gibson ${ }^{2}$, Gábor Cech $^{3}$, Melitta Papp ${ }^{4}$, Petra Deák-Paulus ${ }^{4}$, Lajos Juhász ${ }^{5}$, \\ Norbert Tóth ${ }^{5}$ and Csaba Székely ${ }^{3}$
}

\author{
${ }^{1}$ Institute for Veterinary Medical Research, Centre for Agricultural Research, Hungarian Academy of Sciences - Fish Pathology and \\ Parasitology, Budapest, Hungary; \\ ${ }^{2}$ Department of Life Sciences, Natural History Museum, London, United Kingdom; \\ ${ }^{3}$ Institute for Veterinary Medical Research, Centre for Agricultural Research, Hungarian Academy of Sciences, Budapest, Hungary; \\ ${ }^{4}$ National Food Chain Safety Office - Veterinary Diagnostic Directorate, Budapest, Hungary; \\ ${ }^{5}$ University of Debrecen, Faculty of Agricultural and Food Sciences and Environmental Management, Department of Nature \\ Conservation Zoology and Game Management, Debrecen, Hungary
}

\begin{abstract}
During a regular veterinary inspection of fishes from Lake Balaton, Hungary, echinostomatid metacercariae (Digenea), with collar spines characteristic of species of the genera Petasiger Dietz, 1909 and Paryphostomum Dietz, 1909, were found in the lateral line scales of a roach Rutilus rutilus (Linnaeus), an apparently unique site. In a subsequent examination of 586 fishes from 20 different species, similar infections were found in 11 species. The infection was virtually restricted to the lateral line scales, other scales being infected only incidentally. These encysted metacercariae had 27 collar spines, including eight larger angle spines and 19 smaller dorsal spines arranged in two rows. Two types of metacercarial cyst were found. One type had a cyst diameter of $138-171 \mu \mathrm{m}$ $\times 105-120 \mu \mathrm{m}$ and three central dorsal spines that were larger than the remainder and tended to resemble the angle spines. The second type of metacercarial cyst had a diameter of $128-157 \mu \mathrm{m} \times 105-115 \mu \mathrm{m}$ and all 19 dorsal spines of the metacercaria were of a similar size. ITS sequences of the second type of metacercaria exhibited a $100 \%$ similarity to sequences of two adult Petasiger phalacrocoracis (Yamaguti, 1939) specimens collected from the gut of Phalacrocorax carbo (Linnaeus) in Hungary and to P. phalacrocoracis deposited in the GenBank database. Sequences obtained from two metacercariae of the first type showed a $2.8-2.9 \%$ difference from sequences of the second type of metacercaria and from those of adult specimens of $P$. phalacrocoracis from cormorants. Based on these results, the second type metacercaria is considered to be a larval stage of $P$. phalacrocoracis, but the identity of the first type is uncertain. The unusual location of these metacercariae in the lateral line scales is discussed in relation to their transmission.
\end{abstract}

Keywords: metacercaria, Cyprinidae, Lake Balaton, molecular identification, Kis-Balaton Reservoir

Metacercariae of the digenean family Echinostomatidae Looss, 1899 are frequently encountered encysted in fishes. The number and shape of their head-collar spines are useful diagnostic features for identifying both adult and developing stages, and 27 head-collar spines are characteristic of some species of Petasiger Dietz, 1909 and Paryphostomum Dietz, 1909. Petasiger spp. are common and widely distributed trematode parasites present in the intestine of cormorants and other piscivorous birds. Recently, Faltýnková et al. (2008), in a revision of Petasiger, reported 18 valid species of this genus, mostly from grebes Podiceps spp. Twenty-seven spines on the head collar are known in Europe only for Petasiger exaeretus Dietz, 1909 and P. phalacrocoracis (Yamaguti,
1939), both parasites of cormorants Phalacrocorax spp. According to Našincová et al. (1994), P. phalacrocoracis differs from $P$. exaeretus in relation to its smaller collar spines.

Most of our knowledge of Petasiger spp. relates to the adult stage (Našincová et al. 1994, Kostadinova et al. 2005, Faltýnková et al. 2008) and their life cycles (Karmanova 1971, Kostadinova and Chipev 1992, King and Van As, 2000, Georgieva et al. 2012). Useful data on the metacercarial stage in their fish second intermediate hosts have been presented by Karmanova (1971) and Georgieva et al. (2012).

Hungarian records of Petasiger spp. bearing 27 collar spines are limited to Kotlán's (1922) report of P. phalac-

Address for correspondence: C. Székely, Institute for Veterinary Medical Research, Centre for Agricultural Research, Hungarian Academy of Sciences - Fish Pathology and Parasitology Research Team Hungária krt. 21. Budapest 1143 Hungary Phone: +36-1-4674065; Fax: +36-1-4674076; E-mail: szekely.csaba@agrar.mta.hu 
rocoracis (as $P$. exaeretus - see Faltýnková et al. 2008) in piscivorous birds. There are no records of the metacercarial stages of Petasiger spp., despite the numerous large surveys of trematode infections in fishes that have been carried out in Lake Balaton (e.g. Molnár and Székely 1995, Székely and Molnár 1997). Paryphostomum radiatum (Dujardin, 1845) is a common parasite of cormorants in Europe and has been reported in Hungary by Murai et al. (1983).

With regard to Petasiger spp., the life cycle of $P$. neocomense Fuhrmann, 1927 was studied in detail by Karmanova (1971), who described the metacercaria from fishes. In Europe, the life cycle of Paryphostomum radiatum was studied experimentally by Našincová et al. (1993), who successfully achieved infections in several snail first intermediate hosts and found metacercariae in all 10 fish species (mainly cyprinids) studied. These metacercariae were recovered from the nares, orbits, skin (especially around the mouth) and gills.

Here we report the finding of large numbers of metacercariae in specialised scales covering the lateral line sense organs of cyprinid fishes. By applying sequence data of the ITS region (including part of 18S rDNA, ITS1, 5.8S rDNA, ITS2 and part of $28 \mathrm{~S}$ rDNA), we show that some of these larvae bearing 27 collar-spines represent the metacercarial stage of $P$. phalacrocoracis. In an extensive series of investigations which followed the first finding, we document the high prevalence of these parasites in this unusual site in a range of different fish species, and comment on the utility of this site in relation to transmission.

\section{MATERIALS AND METHODS}

During regular veterinary surveys of fishes of Lake Balaton (including the Kis-Balaton Reservoir), Hungary, we collected data on their parasite fauna. Fishes of different sizes of the most common species in the lake were either caught by small seine nets or acquired from fishermen. The fish were taken to the laboratory live in oxygenated plastic bags, where they were sedated with clove oil, killed with a cervical cut and then subjected to a complete parasitological examination. Samples from different organs were examined under a dissecting microscope and the results recorded. In cases where a rare or unknown parasite species was found, a more detailed examination under a compound microscope was undertaken.

After finding the first metacercariae in lateral line scales, provisionally identified in 2012 as Paryphostomum radiatum, a detailed investigation of these larvae was initiated in order to evaluate the infection statistically. In total, 586 fishes of 20 different species collected from different parts of Lake Balaton (Table 1) were examined. As a control, samples from the Rivers Danube and Tisa and from local fish farms were also studied. During this survey, at least 20 scales from the lateral line and a further 20 from other parts of the fish were examined. In addition, in all cases, pieces of gill, muscle and tissue scrapings from the nares were checked.

Metacercariae removed from the lateral line organ using a needle under a stereo microscope were pipetted onto a glass slide. They were then covered by a coverslip and slightly compressed. Metacercariae were freed from some of the cysts by gently mov- ing the coverslip and crushing the cyst wall. The collar spines of the metacercariae were studied using an Olympus BH2 microscope with differential interference contrast optics. Both encysted and excysted metacercariae were photographed with an Olympus DP20 digital camera from which digitised images were obtained; measurements were taken using IMAGO ${ }^{\circledR}$ software. All measurements are given in micrometres unless otherwise indicated. For species identification, the keys of Kostadinova et al. (2002) and Faltýnková et al. (2008) were used.

For molecular studies, metacercariae freed from fish scales were collected in Eppendorf tubes in 70\% alcohol. In total, seven samples were sent for molecular examination. Two of the samples had 16 cysts (CK1 and CK2), which had been randomly collected from the scales of a roach Rutilus rutilus (Linnaeus) and rudd Scardinius erythrophthalmus (Linnaeus). In addition, five single specimens collected from four roach and a white bream Abramis bjoerkna (Linnaeus) were selected. These five single samples represented two types of metacercariae, two of them with larger, uneven dorsal spines and three with similarly sized dorsal spines.

In addition, intestines of six Phalacrocorax carbo (Linnaeus) specimens shot in Lake Balaton and six other specimens from the Hortobágy fish ponds in eastern Hungary were examined for infections with adult stages of echinostomatids. The intestines of the birds, without the stomach, were sent to the laboratory deepfrozen. After thawing, each intestine was cut open along its full length and its contents washed into a 1 litre glass beaker; the water was changed several times and the sediment checked for the presence of parasites. The trematodes found were studied unfixed and identified using the keys of Kostadinova (2005), Kostadinova et al. (2002) and Faltýnková et al. (2008). From the identified specimens, two Petasiger phalacrocoracis and three Paryphostomum radiatum, were selected for molecular studies. The remainder of the worms was fixed and preserved in $70 \%$ alcohol for further examination.

\section{Molecular methods}

For DNA extraction, samples preserved in ethanol were centrifuged at $8000 \times g$ for $5 \mathrm{~min}$, after which the ethanol was removed. The DNA was extracted using a QIAGEN DNeasy ${ }^{\mathrm{TM}}$ tissue kit (animal tissue protocol; Qiagen, Hilden, Germany) and eluted in $100 \mu \mathrm{AE}$ buffer. The ITS region (part of 18S rDNA, ITS1, 5.8S rDNA, ITS2 and part of 28S rDNA) was amplified via a nested PCR. The primers S18 (5'-TAACAGGTCTGTGATGCC-3') and L3T (5'-CAACTTTCCCTCACGGTACTTG-3') (Jousson et al. 1999) were used in the first run in a $25 \mu 1$ reaction mixture comprised of $2 \mu \mathrm{l}$ of extracted genomic DNA, $5 \mu \mathrm{l}$ of $1 \mathrm{mM}$ dNTPs (MBI Fermentas, Burlington, Canada), $0.25 \mu \mathrm{l}$ of each primer, $2.5 \mu \mathrm{l}$ of $10 \times$ Taq buffer (MBI Fermentas), $0.1 \mu 1$ of DreamTaq polymerase ( $0.5 \mathrm{U}$ ) (MBI Fermentas) and $15 \mu \mathrm{l}$ of water. The PCR profile consisted of an initial denaturation step of $95^{\circ} \mathrm{C}$ for $3 \mathrm{~min}$, followed by 40 cycles of $95^{\circ} \mathrm{C}$ for $30 \mathrm{~s}, 50^{\circ} \mathrm{C}$ for $30 \mathrm{~s}, 72^{\circ} \mathrm{C}$ for $2 \mathrm{~min}$ and was finished with a terminal extension at $72{ }^{\circ} \mathrm{C}$ for $5 \mathrm{~min}$, then stored at $4^{\circ} \mathrm{C}$. The primers D1 ( $5^{\prime}-\mathrm{AG}$ GAATTCCTGGTAAGTGCAA-3') and D2 (5'-CGT TAC TGA GGG AAT CCT GGT-3') (Galazzo et al. 2002) were used in the second run in $50 \mu \mathrm{l}$ of reaction mixture comprised of $1 \mu \mathrm{l}$ PCR product from the first run, $10 \mu \mathrm{l}$ of $1 \mathrm{mM}$ dNTPs (MBI Fermentas), $0.5 \mu$ of each primer, $5 \mu$ of $10 \times$ Taq buffer (MBI Fermentas), $0.2 \mu$ of DreamTaq polymerase ( $1 \mathrm{U}$ ) (MBI Fermentas) and 
Table 1. Infection of the lateral line scales of fishes with echinostomatid metacercariae collected from various natural waters and fish farms in Hungary (positive sites are marked in bold).

\begin{tabular}{|c|c|c|c|c|c|}
\hline Fish species & Collection sites & $\begin{array}{l}\text { No. fish infected/ } \\
\text { No. examined }\end{array}$ & $\begin{array}{l}\text { Fish length } \\
(\mathrm{cm})\end{array}$ & $\begin{array}{l}\text { Infected lateral line } \\
\text { scales (\%) }\end{array}$ & $\begin{array}{l}\text { Mean and range of } \\
\text { metacercariae in scales }\end{array}$ \\
\hline \multirow[t]{2}{*}{ Rutilus rutilus (Linnaeus) } & $\mathbf{K}, \mathbf{K B}, \mathbf{S z}, \mathbf{T i}$ & $55 / 74$ & $7-13$ & 55 & $1-5(2.0)$ \\
\hline & $\mathbf{D}, \mathbf{K}, \mathbf{S z}, \mathbf{T}, \mathbf{T i}, \mathbf{U}$ & $19 / 23$ & $15-30$ & 45 & $1-6(2.2)$ \\
\hline \multirow[t]{2}{*}{ Scardinius erythrophthalmus (Linnaeus) } & $\mathbf{K}, \mathbf{T}, \mathbf{T i}, \mathbf{U}$ & $6 / 6$ & $7-12$ & 60 & $1-7(1.9)$ \\
\hline & $\mathbf{K}, \mathbf{T}, \mathrm{Ti}$ & $6 / 8$ & $16-30$ & 60 & $1-6(2.1)$ \\
\hline \multirow[t]{2}{*}{ Carassius auratus gibelio (Bloch) } & $\mathbf{K}, \mathbf{R}, \mathrm{Ti}, \mathrm{U}$ & $3 / 21$ & $10-14$ & 30 & $1-2(1.2)$ \\
\hline & $\mathrm{K}, \mathrm{KB}$ & $0 / 7$ & $31-35$ & 0 & 0 \\
\hline \multirow[t]{2}{*}{ Cyprinus carpio Linnaeus } & $\mathbf{F}$ & $2 / 81$ & $15-18$ & 5 & $1(1)$ \\
\hline & $\mathbf{K B}, \mathrm{S}$ & $4 / 7$ & $45-55$ & 65 & $1-6(2.5)$ \\
\hline Tinca tinca (Linnaeus) & $\mathbf{K}, \mathbf{K B}$ & $2 / 2$ & $20-22$ & 65 & $1-4(1.3)$ \\
\hline Rhodeus sericeus (Pallas) & $\mathbf{K}$ & $5 / 5$ & $4-7$ & 75 & $1-6(2.0)$ \\
\hline Ballerus sapa (Pallas) & $\mathbf{T}$ & $2 / 2$ & $30-31$ & 5 & 1 \\
\hline Ballerus ballerus (Linnaeus) & $\mathbf{D}, \mathrm{T}$ & $1 / 6$ & $31-32$ & 5 & 1 \\
\hline \multirow[t]{2}{*}{ Abramis bjoerkna (Linnaeus) } & $\mathrm{K}, \mathrm{Sz}, \mathrm{U}$ & $0 / 18$ & $7-12$ & 0 & 0 \\
\hline & $\mathrm{F}, \mathrm{K}, \mathrm{S}, \mathrm{T}, \mathrm{Ti}, \mathrm{U}$ & $1 / 18$ & $16-30$ & 10 & 1 \\
\hline Abramis brama (Linnaeus) & $\mathrm{F}, \mathrm{K}, \mathrm{S}, \mathrm{T}, \mathrm{Ti}, \mathrm{U}$ & $0 / 117$ & $12-50$ & 0 & 0 \\
\hline Alburnus alburnus (Linnaeus) & $\mathrm{K}, \mathrm{Ti}, \mathrm{U}$ & $0 / 56$ & $7-13$ & 0 & 0 \\
\hline Chondrostoma nasus (Linnaeus) & $\mathrm{D}$ & $0 / 4$ & $40-44$ & 0 & 0 \\
\hline Barbus barbus (Linnaeus) & $\mathrm{D}$ & $0 / 2$ & $50-52$ & 0 & 0 \\
\hline Hypophthalmichthys nobilis (Richardson) & $\mathrm{F}$ & $0 / 3$ & $28-30$ & 0 & 0 \\
\hline Ctenopharyngodon idellus (Valenciennes) & $\mathrm{F}$ & $0 / 3$ & $28-31$ & 0 & 0 \\
\hline Lepomis gibbosus (Linnaeus) & $\mathbf{K}, \mathbf{T i}$ & $3 / 12$ & $7-16$ & 20 & $1-3(1.2)$ \\
\hline Sander lucioperca (Linnaeus) & $\mathbf{F}, \mathrm{K}$ & $1 / 9$ & $28-36$ & 5 & 1 \\
\hline Perca fluviatilis Linnaeus & $\mathrm{K}, \mathrm{Ti}, \mathrm{U}$ & $0 / 13$ & $8-10$ & 0 & 0 \\
\hline Anguilla anguilla (Linnaeus) & $\mathrm{F}, \mathrm{K}, \mathrm{Ti}$ & $0 / 9$ & 9 & 0 & 0 \\
\hline Neogobius fluviatilis (Pallas) & $\mathrm{K}, \mathrm{KB}, \mathrm{Sz}, \mathrm{Ti}$ & $0 / 80$ & $6-14$ & 0 & 0 \\
\hline
\end{tabular}

D - River Danube; F - Fish-farms; K - Keszthely; KB - Kis-Balaton; R - Rétimajor Fish Farm; S - Siófok; Sz - Balatonszemes; T - River Tisza; Ti - Tihany; U - Balatonújhely.

$33 \mu \mathrm{l}$ of water. The second PCR consisted of an initial denaturation step of $95^{\circ} \mathrm{C}$ for $3 \mathrm{~min}$, followed by 30 cycles of $95^{\circ} \mathrm{C}$ for $30 \mathrm{~s}, 56^{\circ} \mathrm{C}$ for $30 \mathrm{~s}, 72^{\circ} \mathrm{C}$ for $2 \mathrm{~min}$ and a final extension step at $72{ }^{\circ} \mathrm{C}$ for $5 \mathrm{~min}$, then stored at $4{ }^{\circ} \mathrm{C}$. PCR products were electrophoresed in 1.0\% agarose gels in Tris-Acetate-EDTA (TAE) buffer gel stained with $1 \%$ ethidium bromide and then purified with an EZ-10 Spin Column PCR Purification Kit (Bio Basic Inc., Markham, Canada). Purified PCR products were sequenced with the PCR primers D1 and D2 and with two additional inner primers 5.8Sr (5'-TGTCGATGAAGAGCGCAGC-3') and 5.8S2 (5'-TAAGCCGACCCTCGGACAGG-3') (Tkach et al. 2000) using an ABI BigDye Terminator v3.1 Cycle Sequencing Kit with an ABI 3100 Genetic Analyser.

The sequence fragments were assembled using MEGA 6.06 (Tamura et al. 2013) and ambiguous bases clarified using corresponding ABI chromatograms. Nucleotide sequences were aligned with the software CLUSTAL W (Thompson et al. 1994). The alignment was corrected manually using the alignment editor of the software MEGA 6.06. DNA pairwise distances were calculated with the MEGA 6.06 software using the Tamura-Nei substitution model. Maximum likelihood (ML) and Bayesian inference (BI) analyses were performed. The liver fluke, Fasciola hepatica Linnaeus, 1758, was chosen as the outgroup. The dataset was tested using MEGA 6.06 for the nucleotide substitution model of best fit and the model, shown by the Akaike Information Criterion (AIC) as the best-fitting one, was chosen for each partition. ML analyses were performed in MEGA 6.06 under the GTR + G model. Bootstrap values based on 1000 resampled datasets were generated. BI was computed by Topali 2.5 (Milne et al. 2004) The likelihood parameters for BI were based on the GTR $+\mathrm{G}$ model.
Posterior probabilities (PP) were estimated over 1000000 generations via two independent runs of four simultaneous MCMCMC chains with every 100 th tree saved. The first $25 \%$ of the sampled trees were discarded as 'burn in'. The ML tree was visualised using the tree explorer of MEGA 6.06.

\section{RESULTS}

Our first finding, an intensive infection with an echinostome type of metacercariae bearing collar spines at the anterior end, was in a $10 \mathrm{~cm}$ long (age $1+$ ) roach Rutilus rutilus. In this fish several dozen metacercariae were found in scales covering the lateral lines. No infection was recorded in other scales of the fish. Two morphotypes were found among the metacercariae. The first had an ellipsoidal shape, a thin cyst wall and measured 138-171 in length and 105-120 in width (Fig. 1). They were sometimes surrounded by a thick capsule formed by the host (Fig. 2). Metacercariae released from these cysts measured 430-490 × 118-123 (Fig. 3). These worms had 27 collar spines, including 19 dorsal spines in two alternate rows and four pairs (2 pairs on each side) of larger angle spines. Sixteen of the dorsal spines had a length of 17-26 and the angle spines were 34-45 long. In these specimens, three of the dorsal spines located centrally proved to be larger, measuring 33-40 (Fig. 5). The second morphotype had a cyst size of $128-157 \times 105-115$. These metacercariae also had 27 collar spines: four pairs of angle spines of 28-40 and 19 dorsal spines all of a similar size (17-23) (Fig. 6). Excysted metacercariae of the latter type had a size of 400-450 × 115-123 (Fig. 4). Judging by the shape 


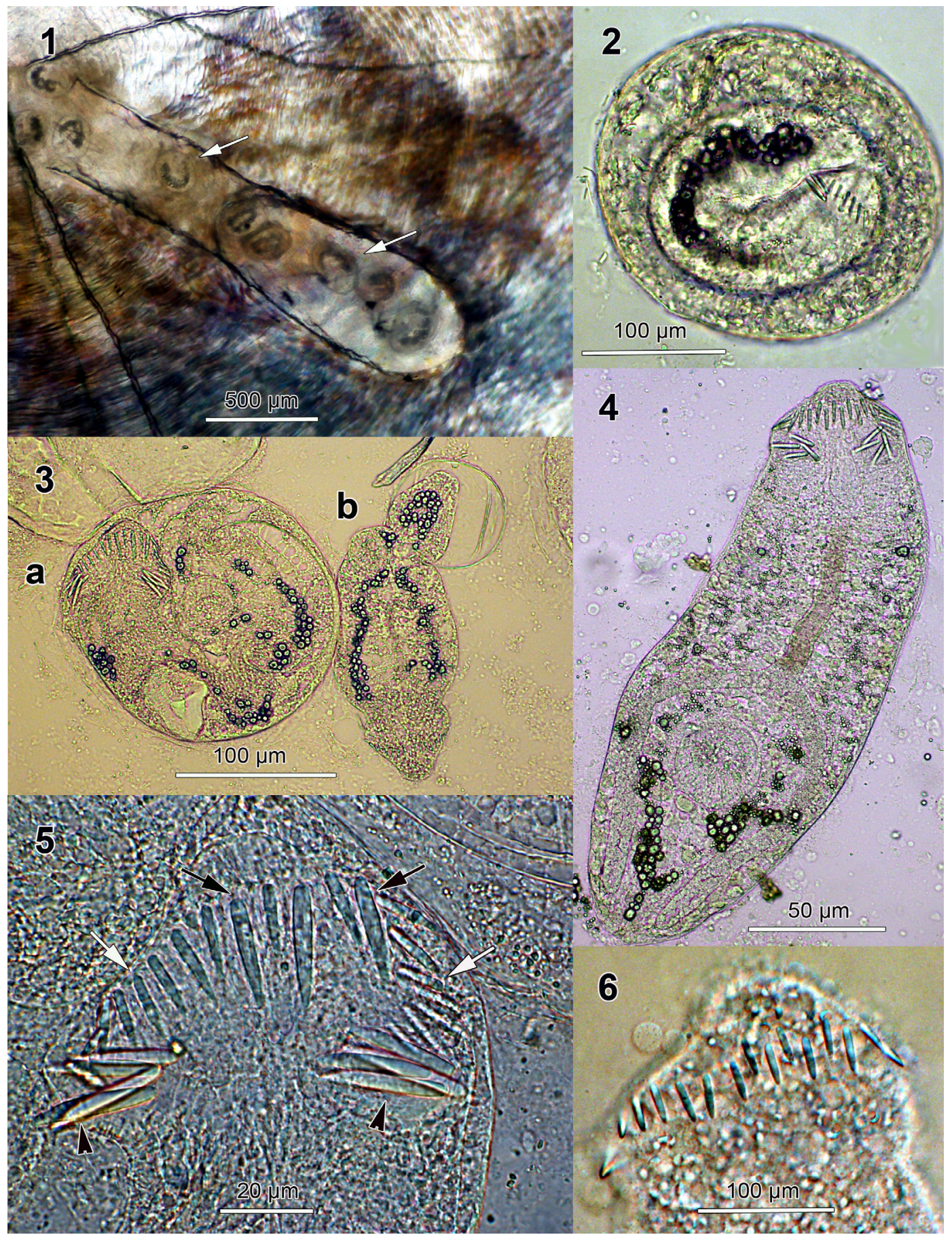

Fig. 1. Lateral line scale of a roach infected with echinostomatid metacercariae (arrows). Fig. 2. Cyst of an echinostomatid metacercaria surrounded by a thick host capsule. Fig. 3. Encysted (a) and excysted (b) metacercariae of the first morphotype echinostomatid metacercaria. Fig. 4. Excysted specimen of the second morphotype of echinostomatid metacercaria. Fig. 5. Collar spines of the first morphotype of echinostomatid metacercaria: angle spines (arrowheads); larger dorsal spines (black arrows); smaller dorsal spines (white arrows). Fig. 6. Collar spines of the second morphotype echinostomatid metacercaria, showing all of the dorsal spines of a similar size.

and number of collar spines, both types of metacercariae could be related to species of either Paryphostomum or two species of Petasiger (P. phalacrocoracis and P. exaeretus).

A survey initiated for measuring the infection levels in different species and sizes of fishes (Table 1) showed that this type of metacercarial infection is both common and intense in different fish species, and that its finding is dependent upon the method of parasitological investigation, namely a detailed examination of the specialised scales covering the lateral line organs. Infections associated with other scales were encountered only rarely.

The metacercariae were localised arranged in-line within a tube which passes through the scale and forms part of the lateral line canal of the fish (Fig. 1), a feature unique to lateral line scales. 


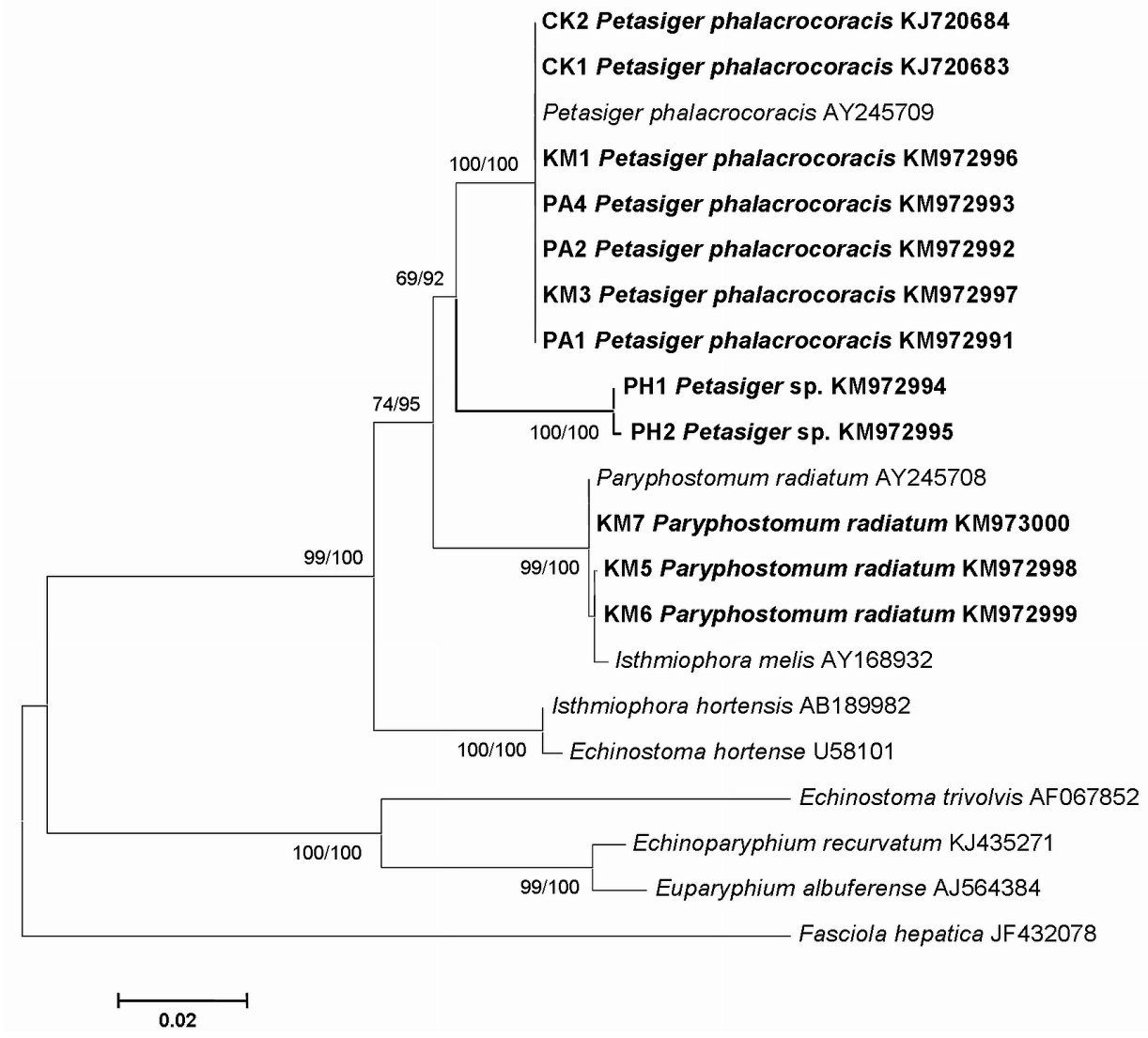

Fig. 7. Maximum likelihood tree of the commonly found echinostomatid metacercariae (PH1, PH2 - morphotype 1; CK1, CK2, PA1, PA2 and PA4 - morphotype 2) from the lateral line scales of roach and adult worms from cormorants (KM1, KM3 - Petasiger phalacrocoracis; KM5-KM7 - Paryphostomum radiatum) and in relation to echinostomatid material deposited in GenBank. Posterior probabilities for Bayesian inference are given behind the bootstrap values for ML. Samples from this study are in bold.

In the present studies, these metacercariae were found in nine cyprinid species (Table 1) and also in a percid fish, the pike perch Sander lucioperca (Linnaeus), and a centrarchid, the pumpkinseed Lepomis gibbosus (Linnaeus). In the case of other fishes common in Lake Balaton and examined in relatively large numbers, no infection was found in bream Abramis brama (Linnaeus), bleak Alburnus alburnus (Linnaeus) and the monkey goby Neogobius fluviatilis (Pallas). Of the leuciscine cyprinid fishes, roach and rudd Scardinius erythrophthalmus exhibited the highest prevalence (45 and $60 \%$, respectively) and intensity (1-7 metacercariae/scale) of infection. Fingerlings and young $(0+)$ fish of the latter two species exhibited no infection, but 2-3 year-old fishes of the same species had high infection levels, harbouring several metacercariae in the lateral line scales. Infections in larger fish decreased and, in fish with more calcified scales, occurred very rarely. Infections associated with scales not linked to the lateral line system were rare (in only $0.28 \%$ of the scales collected from other regions of the body). In addition to the intensively studied fishes of Lake Balaton, similar metacercarial infections were found in fishes from the Rivers Danube and Tisa and in some young $0+$ and $1+$ common carp cultured in fish farms in different regions of Hungary.

Additional studies made on echinostomatid trematodes collected from the gut of 12 Phalacrocorax carbo speci- mens showed that these birds were commonly infected by two types of echinostomatid trematodes. By examining unfixed worms, we identified them morphologically as Paryphostomum radiatum and Petasiger phalacrocoracis. All of the studied birds had an infection of 3-80 (mean 27) specimens of $P$. radiatum, whereas 10 of the birds were infected by 1-150 (mean 31) specimens of $P$. phalacrocoracis.

Two adult Petasiger and three Paryphostomum specimens from the cormorants and seven metacercarial samples from roach, rudd and white bream were sequenced (Table 2). The PCR products were more than 1300 bps long and the alignment containing the examined sequences and those downloaded from GenBank were 1301 bps long. The phylogenetic analysis resulted in robust trees with high bootstrap values for MI and posterior probabilities for BI. The generated ML and BI trees exhibited an identical topology; therefore, only the ML tree is presented (Fig. 7) with the posterior probabilities for BI.

Three sequences obtained from samples of three adult $P$. radiatum specimens (KM972998-KM973000) corresponded $99.9-100 \%$ with sequences of $P$. radiatum (AY245708) and 99.7-99.8\% to Isthmiophora melis (Schrank, 1788) (AY168932) and formed a single clade with a high bootstrap support (Fig. 7). Two sequences from adult P. phalacrocoracis (KM972996, KM972997) corre- 
Table 2. List of the sequenced metacercariae and adult samples.

\begin{tabular}{|c|c|c|c|c|c|}
\hline Sample Species & Host* & Developmental stage & Collection date & Collection site & Accession number \\
\hline Petasiger phalacrocoracis & roach & metacercaria & 10 August 2012 & Keszthely, Lake Balaton, Hungary & KJ720683 \\
\hline Petasiger phalacrocoracis & rudd & metacercaria & 31 May 2012 & Keszthely, Lake Balaton, Hungary & KJ720684 \\
\hline Petasiger phalacrocoracis & roach & metacercaria & 6 May 2014 & Keszthely, Lake Balaton, Hungary & KM972991 \\
\hline Petasiger phalacrocoracis & roach & metacercaria & 28 April 2014 & Keszthely, Lake Balaton, Hungary & KM972992 \\
\hline Petasiger phalacrocoracis & white bream & metacercaria & 5 May 2014 & Keszthely, Lake Balaton, Hungary & KM972993 \\
\hline Petasiger $\mathrm{sp}$. & roach & metacercaria & 28 April 2014 & Keszthely, Lake Balaton, Hungary & KM972994 \\
\hline Petasiger sp. & roach & metacercaria & 6 May 2014 & Keszthely, Lake Balaton, Hungary & KM972995 \\
\hline Petasiger phalacrocoracis & cormorant & adult & 22 April 2014 & Hortobágy, Hungary & KM972996 \\
\hline KM3 Petasiger phalacrocoracis & cormorant & adult & 22 April 2014 & Hortobágy, Hungary & KM972997 \\
\hline Paryphostomum radiatum & cormorant & adult & 22 April 2014 & Hortobágy, Hungary & KM972998 \\
\hline Paryphostomum radiatum & cormorant & adult & 23 April 2014 & Lake Balaton, Hungary & KM972999 \\
\hline KM7 Paryphostomum radiatum & cormorant & adult & 24 April 2014 & Lake Balaton, Hungary & KM973000 \\
\hline
\end{tabular}

* roach - Rutilus rutilus (Linnaeus); rudd - Scardinius erythrophthalmus (Linnaeus); white bream - Abramis bjoerkna (Linnaeus); cormorant - Phalacrocorax carbo (Linnaeus).

sponded $100 \%$ with the $P$. phalacrocoracis (AY245709) sequence deposited in the Genbank database and are located in the same clade (Fig 7).

Sequences of the second type metacercaria (KJ720683, KJ720684, KM972991, KM972992, KM972993), with collar spines resembling P. phalacrocoracis (Fig. 7), exhibited a $100 \%$ identity with the sequences of $P$. phalacrocoracis deposited in GenBank (AY245709) and with the two adult P. phalacrocoracis samples (KM972996, KM972997) collected by ourselves. As to the two samples of the first metacercarial type, the sequences (KM972994, KM972995) exhibited a 97.1-97.2\% similarity with sequences of adult P. phalacrocoracis (KM972996, KM972997). These metacercariae were only 96.0-96.1\% similar to Paryphostomum radiatum (AY245708) and to the adult specimens of this species (KM972998-KM973000) studied by ourselves (Fig. 7). Similarly, they exhibited a $95.0 \%$ and $96.2 \%$ similarity with Isthmiophora melis and I. hortensis (Asada, 1926), respectively, but formed a single clade as a sister branch of Petasiger phalacrocoracis (Fig. 7).

\section{DISCUSSION}

Our morphological investigations of echinostomatid metacercariae infecting the lateral line scales of fishes in Hungary have shown that the number and the structure of their collar spines corresponded to species of Petasiger and/or Paryphostomum, common parasites from the intestine of the piscivorous birds, such as comoronants (Phalacrocorax spp.) and grebes (Podiceps spp.). The number and arrangement of the collar spines of the vast majority of metacercariae recovered from the lateral line scales in the present study agree well with the description of these structures in the generic diagnosis of Paryphostomum given by Kostadinova (2005) and with description of two species of the genus Petasiger, i.e. P. exaeretus and P. phalacrocoracis, as revised by Faltýnková et al. (2008). Although most Petasiger species have 19-23 collar spines, the latter two species are armed with 27 collar spines, like the present material. The arrangements of the collar spines fit well with the illustrations of the latter two species and with those of Paryphostomum radiatum given by Našincová et al. (1993) and Kostadinova (2005). However, our molecu- lar studies have shown that sequences of these metacercariae correspond more closely to sequences of species of Petasiger and differ from sequences of Paryphostomum radiatum deposited in GenBank. Our examinations of echinostomatids from the intestines of cormorants in Hungary showed that these birds were infected by adult specimens of Petasiger and Paryphostomum, which we identified as Petasiger phalacrocoracis and Paryphostomum radiatum. Our molecular sequences from the latter confirmed these identifications.

Sequences of the second metacercarial morphotype collected from within the lateral line scales correspond exactly to the sequences of adult specimens of $P$. phalacrocoracis collected from $P h$. carbo by us and also to the sequences deposited in GenBank. Although sequences of the first metacercarial morphotype from the lateral lines scales had some resemblance to sequences of adult Petasiger phalacrocoracis, the $2.8-2.9 \%$ difference suggests that they may be metacercariae of another species of Petasiger or even another genus. The $\mathrm{ca} 4 \%$ difference between these sequences and sequences of adult $P$. radiatum from the gut of cormorants invalidates our initial supposition that they were a developmental stage of a species of Paryphostomum. It is clear that molecular data are needed for more adult echinostomatids in order to solve this problem. This applies especially of Petasiger exaeretus, which is less frequently found than P. phalacrocoracis (see Našincová et al. 1994), since there are only two known species of Petasiger with 27 collar spines reported from Europe (Faltýnková et al. 2008). Nevertheless, it should be noted that enlarged mid-dorsal spines were not reported in the adult of this species by Našincová et al. (1994).

Lateral lines scales are unusual and differ from other scales in that they contain a tube, through which the lateral line canal (trunk canal) passes, with anterior and posterior apertures (DeLamater and Courtenay 1973, Voronina and Hughes 2011). Those of numerous cyprinids have been described in detail (Esmaeili and Gholami 2011, Voronina and Hughes 2011). It would appear that the lateral line canal within the scales represents a very suitable space for metacercariae to develop. Furthermore, the fact that the scales have pores connected to the lateral line canal means 
that the cercariae have a ready route of access during transmission.

The presence of so many metacercariae within the lateral line canal begs the question as to whether they affect the functioning of the system. Certainly, it would seem likely that a heavy infection might affect the pressure differential between the pores and thus the flow of canal fluid along the canal past the mechanoreceptor (neuromast). Hence, the fish may not be as successful in detecting prey or indeed predators, the latter of which might be beneficial to the parasite.

Acknowledgement.This research was supported by the Hungarian Scientific Research Fund (OTKA) grants K 100132, PD 108813 and KTIA-AIK-12-1-2013-0017.

\section{REFERENCES}

DeLamater E.D., Courtenay W.R., Jr. 1973: Variations in structure of the lateral-line canal on scales of teleostean fishes. Z. Morph. Tiere 75: 259-266.

Esmaeili H.R., Gholami Z. 2011: Scanning electron microscopy of the scale morphology in cyprinid fish, Rutilus frisii kutum Kamenskii, 1901 (Actinopterygii: Cyprinidae). Iranian J. Fisher. Sci. 10: 155-166.

Faltýnková A., Gibson D.I., Kostadinova A. 2008: A revision of Petasiger Dietz, 1909 (Digenea: Echinostomatidae) and a key to its species. Syst. Parasitol. 71: 1-40.

Galazzo D.E., Dayanandan S., Marcogliese D.J., McLaughLIN J.D. 2002: Molecular systematics of some North American species of Diplostomum (Digenea) based on rDNA-sequence data and comparisons with European congeners. Can. J. Zool. 80: 2207-2217

Georgieva S., Kostadinova A., Skirnisson K. 2012: The life cycle of Petasiger islandicus Kostadinova \& Skirmisson, 2007 (Digenea: Echinostomatidae) elucidated with the aid of molecular data. Syst. Parasitol. 82: 177-183.

Jousson O., Bartoli P., Pawlowski J. 1999: Molecular identification of developmental stages in Opecoelidae (Digenea). Int. J. Parasitol. 29: 1853-1858.

Karmanova E.M. 1971: [The life cycle of Petasiger neocomense (Trematoda, Echinostomatidae).] Trudy Gel'mintol. Lab. Akad. nauk SSSR 21: 31-35 (In Russian.)

King P.H., VAn As J.G. 2000: Morphology and life history of Petasiger variospinosus (Trematoda: Echinostomatidae) in the Free State, South Africa. J. Parasitol. 86: 312-318.

Kostadinova A. 2005: Family Echinostomatidae. In: A. Jones, R.A. Bray and D.I. Gibson (Eds.), Key to the Trematoda. Vol. 2. CAB International, Wallingford and Natural History Museum, London, pp. 9-64.

Kostadinova A., Chipev N. 1992: Experimental data on the lifecycle of Petasiger grandivesicularis Ishii, 1935 (Trematoda: Echinostomatidae). Syst. Parasitol. 23: 55-65.

Kostadinova A., Vaucher C., Gibson D.I. 2002: Redescriptions of two echinostomes from birds in Paraguay, with comments on Drepanocephalus Dietz, 1909 and Paryphostomum Dietz, 1909 (Digenea: Echinostomatidae). Syst. Parasitol. 53: 147-158.
Kotlán S. 1922: Beiträge zur Kentniss der Trematoden. Zool. Jahrb. Syst. 45: 565-576.

Milne I., Wright F., Rowe G., Marshal D.F., Husmeier D., McGuire G. 2004: TOPALi: Software for Automatic Identification of Recombinant Sequences within DNA Multiple Alignments, Bioinformatics 20: 1806-1807.

Molnár, K., Székely C. 1995: Parasitological survey of some important fish species of Lake Balaton. Parasitol. Hung. 28: 63-82.

Murai E., Sulgostowska T., Matskási I., Mészáros F., MolNÁR K. 1983. Parasitic helminths of vertebrates (fishes, amphibians, reptiles and birds) in the Hortobagy National Park. In: S. Mahunka (Ed.), The Fauna of the Hortobágy National Park. Volume II. Akadémiai Kiadó, Budapest, pp. 15-30.

Našincová V., Scholz T., Moravec F. 1993: The life cycle of Paryphostomum radiatum (Dujardin, 1845) (Trematoda: Echinostomatidae), a parasite of cormorants. Folia Parasitol. 40: 193-201.

Našincová V., Scholz T., Moravec F. 1994: Redescription of Petasiger exaeretus Dietz, 1909 and P. phalacrocoracis (Yamaguti, 1939) (Trematoda: Echinostomatidae), parasites of cormorants. Syst Parasitol 27: 139-147.

Székely C., Molnár K. 1997: Preliminary survey of the parasite fauna of some important fish species in the Upper-Reservoir of the Kis-Balaton System. Parasitol. Hung. 29-30: 45-54.

Tamura K., Stecher G., Peterson D., Filipski A., Kumar S. 2013: MEGA6: Molecular Evolutionary Genetics Analysis, version 6.0. Mol. Biol. Evol. 30: 2725-2729.

Thompson J.D., Higgins D.G., Gibson T.J. 1994: CLUSTALW: improving the sensitivity of progressive multiple sequence alignment through sequence weighting, position-specific gap penalties and weight matrix choice. Nucl. Acids Res. 22: 4673-4680.

Tкасн V.V., Pawlowski J., Sharpilo V.P. 2000: Molecular and morphological differentiation between species of the Plagiorchis vespertilionis group (Digenea, Plagiorchiidae) occurring in European bats, with a redescription of $P$. vespertilionis (Müller, 1780). Syst. Parasitol. 47: 9-22.

Voronina E.P., Hughes D.R. 2011: Types and development pathways of lateral line scales in some teleost species. Acta Zool. 94: 154-166. 